\title{
A FRAMEWORK FOR COMMINUTION CIRCUITS DESIGN EVALUATION USING GREY COMPROMISE PROGRAMMING
}

\author{
Dragisa Stanujkic ${ }^{1}$, Sanja Stojanovic ${ }^{2}$, Rodoljub Jovanovic ${ }^{3}$, \\ Nedeljko Magdalinovic ${ }^{4}$ \\ Faculty of Management Zajecar, Megatrend University, \\ Park Suma Kraljevica b.b., 19000 Zajecar, Serbia \\ E-mails: ${ }^{1}$ dragisa.stanujkic@fmz.edu.rs (corresponding author); \\ ${ }^{2}$ sanja.stojanovic@fmz.edu.rs; ${ }^{3}$ rodoljub.jovanovic@fmz.edu.rs; \\ ${ }^{4}$ nedeljko.magdalinovic@fmz.edu.rs \\ Received 17 May 2012; accepted 09 August 2012
}

\begin{abstract}
Comminution process, particularly grinding, is very important in the mineral processing industry. Some characteristics of ore particles, which occur as a product of grinding process, have a significant impact on the effects of further ore processing. At the same time, this process requires a significant amount of energy and also significantly affects the overall processing costs. Therefore, in this paper, we propose new multiple criteria decision making model based on grey compromise programming for adequate comminution circuit design selection.

Although it is based on a simple procedure, we consider that the proposed model is efficient and flexible, and that it also represents the basis for forming more sophisticated models for comminution circuit design selection, as in addition, many other decision making problems in business environment, which is characterized by predictions and uncertainty.
\end{abstract}

Keywords: MCDM, interval grey numbers, compromise programming, uncertainty, mineral processing, comminution circuit selection.

Reference to this paper should be made as follows: Stanujkic, D.; Stojanovic, S.; Jovanovic, R.; Magdalinovic, N. 2013. A framework for Comminution Circuits Design evaluation using grey compromise programming, Journal of Business Economics and Management 14(Supplement 1): S188-S212.

JEL Classification: D81, C61, C44.

\section{Introduction}

The comminution and grinding processes are very important in the mineral processing industry. During these processes, ore particle size reduction is done to ensure the conditions for efficient liberation of commercially valuable minerals from gangue, in the next stage of ore processing. It is very important that grounded ore has adequate particle size distribution.

Grinding requires significant amounts of energy consumption, which significantly affects the processing costs in many ways. In addition, the grinding process often requires 
the use of grinding media, such as balls or rods, which also has an impact on the processing costs.

In order to reduce processing costs, ensure the appropriate particle size distribution of milled ore and provide the necessary plant throughput, during the time, it was formed more than one device for crushing and grinding ore, of which we mention: autogenous (AG) mills, semi-autogenous (SAG) mills, ball mills, pebble mills and rod mills. As a result it was formed several typicall Grinding Circuit Designs (GCD), and a significant number of their variants.

After a detailed consideration of literature, we noted with some regret, that papers which directly consider selection of GCD are very rare (such as Putland 2006). In the literature there are papers and researches which consider selection of GCD, but they mainly consider optimizations or contain comparisons of some GCD for conditions which exist in a particular mine (such as Ergun et al. 2004; Ahmadabadi et al. 2008).

Selection of the appropriate GCD can greatly affect decreasing of production costs, such as lower energy consumption and grinding media consumption. However, the reduction of production costs, during the separation of valuable metals from ores, is not the only goal that should be achieved.

If we take into account that ores with high content of valuable minerals were already excavated and processed, and that we have now very limited quantities of ores with low content of valuable minerals, lower production costs with, at the same time, lower utilization of valuable components cannot be considered as the best and the smartest choice.

GCD include a significant amount of heavy, and of course, expensive equipment. Therefore, it is quite reasonable aspiration to reduce the amount of money that will be spent into building of the plant. However, from a long-term perspective, the higher levels of capital investment costs can provide a lower production costs and/or better valuable minerals utilization.

Equipment used in the GCD is exposed to high loads, and therefore requires a significant and intensive maintenance. During the maintenance, plant is unable to perform processing of ore, which can have very significant effect to the total revenues.

Generally, in the case of GCD selecting there exist several mutually conflicting criteria, and therefore we propose to consider this problem as a multiple criteria decision making problem.

In the case of GCD selecting, some performance ratings of alternatives sometimes can not be precisely determined because their values are obtained based on the assessments of one or more experts. In addition, some characteristics that are used for selection, such as some characteristics of ore, may be variable over time. Therefore we propose to consider selection of GCD as a decision making problem under uncertainty.

Finally, when selecting the GCD, in order to obtain more realistic results and achieve adequate selection of GCD, it is often necessary to consider opinions and attitudes of more experts. Therefore we propose to consider selection of GCD as a group decision making problem. 
As a result of the above mentioned, we propose to consider GCD selection as multiple criteria group decision making problem under uncertainty.

In the mineral processing, GCD can not be easily isolated from a complex system, of which they are very important part. Effects that are achieved based on the application of a GCD have a significant impact on the rest of the ore processing. More precisely, the process of grinding ore and ore particles size distribution may have a significant impact on the rest of the ore processing and extraction of valuable minerals. In addition, some characteristics of the ore, which, after crushing, come in GCD, significantly affect the grinding process, as well as effects that are achieved by applying this process.

Therefore, we also propose that the problem of selection of appropriate GCD should be consider much broader, i.e. as a problem of selection the Comminution Circuits Design (CCD) using a group of multiple criteria group decision making under uncertainty.

Because of all above mentioned reasons, the rest of this manuscript is organized as follow. Some preliminaries significant for the development of the proposed methodology, are given in section 1 . Thus, in subsection 1.1 the basic elements of grey system theory are considered, while in section 1.2 compromise programming is presented. In section 2 , a framework for $\mathrm{CCD}$ evaluation using grey compromise programming is presented. In section 3, a numerical example is considered with the aim to explain in details the proposed methodology. Finally the conclusions are given.

\section{Preliminaries}

In the past few decades, the multiple criteria decision making (MCDM) was developed rapidly. As a result, numerous multiple criteria decision making methods have been formed. At the beginning, these methods were based on the use of crisp performance ratings and crisp weights. However, many real-world decision making problems are complex and often associated with some forms of uncertainties and therefore these methods do not give always satisfactory results.

To provide the ability to deal with uncertainties, Zadeh (1965) introduced fuzzy set theory, after which Bellman and Zadeh (1970) proposed the decision making in a fuzzy environment.

In contrast to the classical set theory, fuzzy set theory allows partial membership to sets and also introduces several forms of fuzzy numbers. Compared to the crisp numbers, fuzzy numbers enable creation of much more realistic models of complex problems and therefore the fuzzy MCDM approach has became the useful tool for solving many real world decision making problems.

Another important approach was proposed by Deng (1982). Similarly to the fuzzy set theory, Deng (1982) proposed grey system theory, which allows the decision making with lack of some required information.

Based on mentioned theories, a number of ordinary MCDM methods are extended, with the aim to allow the use of fuzzy or interval grey numbers. 


\subsection{Grey systems theory and grey numbers}

Unlike the classical set theory, in grey system theory required information may be partially or even fully unknown. The use of partially known information enables the formation of more realistic models of complex real-world decision making problems.

In the grey system theory, the availability of information is associated with the corresponding color. Precise information is associated with white color, while unavailable information is associated with black color. Between these colors are placed partially known information, and it is associated with grey color.

Grey system theory also introduces the concept of interval grey numbers. Let $x$ denote a closed and bounded set of real numbers. A grey number $\otimes x$, shown in Figure 1., is defined as an interval with known lower $x$ and upper $\bar{x}$ bounds but unknown distribution information for $x$ (Deng 1989):

$$
\otimes x=[\underline{x}, \bar{x}]=\left[x^{\prime} \in x \mid \underline{x} \leq x^{\prime} \leq \bar{x}\right] .
$$

The greyness of an interval grey number is determined by distance between it bounds. When upper and lower bounds are the equal, $\underline{x}=\bar{x}$, interval grey number becomes a white number, i.e. deterministic number. Otherwise, when distance between bounds increases and bounds tends to infinity, $\underline{x} \rightarrow-\infty$ and $\bar{x} \rightarrow+\infty$, interval grey number becomes a black number.

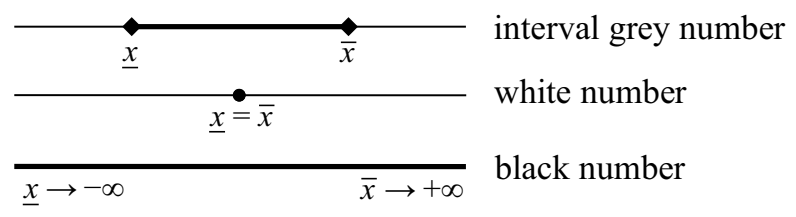

Fig. 1. White, black and interval grey numbers

The width $\otimes x_{\omega}$ of an interval grey number $\otimes x$ is defined as:

$$
\otimes x_{\omega}=\bar{x}-\underline{x} .
$$

The Whitened Mid Value $x_{m}$ of an interval grey number $\otimes x$ is defined as:

$$
x_{m}=0.5(\underline{x}+\bar{x}) .
$$

The grey degree $G d(\otimes x)$ of an interval grey number $\otimes x$ is defined as ratio between its width and Whitened Mid Value (Huang et al. 1995), as follows:

and it is expressed in percentage (\%).

$$
G d(\otimes x)=\frac{x_{\omega}}{x_{m}} \cdot 100
$$

The basic arithmetic operations on the interval grey numbers are partly different in relation to operations on crisp numbers. For given two interval grey numbers $\otimes x_{1}=\left[\underline{x}_{1}, \bar{x}_{1}\right]$ and $\otimes x_{2}=\left[\underline{x}_{2}, \bar{x}_{2}\right]$ some basic operations, used in this paper, are defined as follows (Deng 1992; Liu and Lin 2006): 


$$
\begin{aligned}
& \otimes x_{1}+\otimes x_{2}=\left[\underline{x}_{1}+\underline{x}_{2}, \bar{x}_{1}+\bar{x}_{2}\right], \\
& \otimes x_{1}-\otimes x_{2}=\left[\underline{x}_{1}-\bar{x}_{2}, \bar{x}_{1}-\underline{x}_{2}\right] \text {, } \\
& \otimes x_{1} \times \otimes x_{2}=\left[\underline{x}_{1} \underline{x}_{2}, \bar{x}_{1} \bar{x}_{2}\right], \\
& k \times \otimes x=[k \underline{x}, k \bar{x}], \\
& (\otimes x)^{-1}=[1 / \bar{x}, 1 / \underline{x}] .
\end{aligned}
$$

The transformation of a interval grey number to the appropriate crisp value can be made by using the whitening function, which can be shown as follows (Liu and Lin 2006):

$$
x_{(\lambda)}=\lambda \underline{x}+(1-\lambda) \bar{x}
$$

with $\lambda$ as whitening coefficient and $\lambda \in[0,1]$. Because of its similarity with a widely used $\lambda$, function, formula (10) is often shown in the following form:

$$
x_{(\lambda)}=(1-\lambda) \underline{x}+\lambda \bar{x} .
$$

\subsection{Compromise programming}

The concept of Compromise programming was proposed by Zeleny (1973) and Yu (1973). The basic idea of this MCDM method is to determine the alternative that has the least distance from the ideal solution.

For a multiple criteria decision making problem which include $m$ alternatives that are evaluated in terms of $n$ criteria, compromise programming can be presented as follows:

$$
\min L_{p, i}=\left\{\sum_{j=1}^{n} w_{j}^{p}\left(\frac{x_{j}^{*}-x_{i j}}{x_{j}^{*}-x_{j}^{-}}\right)^{p}\right\}^{\frac{1}{p}},
$$

where $L_{p, j}$ is the distance metric of $i$-th alternative for a given parameter $p, w_{j}$ is the weight of $j$-th criteria; $x_{j}^{*}$ and $x_{j}^{-}$are the best (ideal) and the worst value of $j$-th criterion, respectively; $x_{i j}$ is the performance ratings of $i$-th alternative on $j$-th criterion, $i=1,2, \ldots, m$ and $j=1,2, \ldots, n$.

The parameter $p$, in formula (12) is used to represent the importance of the maximal deviation from the ideal point. By varying the parameter $p$ from 1 to infinity, it is possible to move from minimizing sums of individual deviations to minimizing the maximal deviation to the ideal point, in a decision-making process. The choice of a particular value of this compensation parameter $p$ depends on the type of problem and desired solution (Tecle et al. 1998).

The best $x_{j}^{*}$ and the worst $x_{j}^{-}$performance ratings of $j$-th criterion are determined using the following formulae:

$$
x_{j}^{*}=\left\{\begin{array}{ll}
\max _{i} x_{i j} ; & j \in \Omega_{\max } \\
\min _{i} x_{i j} ; & j \in \Omega_{\min }
\end{array},\right. \text { and }
$$




$$
x_{j}^{-}=\left\{\begin{array}{ll}
\min _{i} x_{i j} ; & j \in \Omega_{\max } \\
\max _{i} x_{i j} ; & j \in \Omega_{\min }
\end{array},\right.
$$

where $\Omega_{\max }$ and $\Omega_{\min }$ are sets of benefit and cost criteria, respectively.

Over time, a number of MCDM methods also are formed, from which we emphasize some of the most prominent, such as: Simple Additive Weighting (SAW) method (MacCrimon 1968), Analytic Hierarchy Process (AHP) method (Saaty 1980), Technique for Ordering Preference by Similarity to Ideal Solution (TOPSIS) method (Hwang, Yoon 1981), Preference Ranking Organisation Method for Enrichment Evaluations (PROMETHEE) method (Brans, Vincke 1985), ELimination and Choice Expressing REality (ELECTRE) method (Roy 1991), COmplex PRoportional ASsessment (COPRAS) method (Zavadskas et al. 1994; Zavadskas et al. 2009b), VIKOR (VIsekriterijumska optimizacija i KOmpromisno Resenje in Serbian, means Multiple criteria Optimization and Compromise Solution ) method (Opricovic 1998), Multi-Objective Optimization on the basis of Ratio Analysis (MOORA) method (Brauers, Zavadskas 2006) and Additive Ratio Assessment (ARAS) method (Zavadskas, Turskis 2010; Zavadskas et al. 2010a; Turskis, Zavadskas 2010).

A comprehensive classification of MCDM methods is given by Zavadskas et al. (2010a) and Turskis and Zavadskas (2010). According to this classification, Compromise programming can be classified into methods based on quantitative measurements, as well as SAW, TOPSIS, VIKOR, COPRAS, MOORA and ARAS method.

However, the above mentioned methods are also based on different approaches; it uses aggregation procedures of different complexity and often different normalization procedures. A comprehensive overview of mentioned methods, and their comparison, is given in Stanujkic et. al (2012).

The SAW method is probably the simplest, best known and previously often used MCDM methods. This method is characterized by simple aggregation procedure and the possibility of applying different normalization procedures. The basic idea of SAW method is that overall ranking index for each alternative is calculated as the sum of products of its performance ratings and weights of criteria, and alternatives with higher values of overall ranking index have higher ranks.

Aggregating procedure of SAW method do not make a difference between cost and benefit criteria. Therefore, during normalization performance ratings of cost criteria also must be transformed into corresponding performance ratings of benefit criteria. The necessity of this kind of transformation is often mentioned as a weakness of the SAW method.

The next characteristic method from the above group is TOPSIS method, as one of the most widely used MCDM method. The basic idea of TOPSIS method is that the best alternative should have the shortest distance from the ideal solution and the farthest distance from the negative-ideal solution, in Euclidean space. 
And finally, the third method, which we consider here is VIKOR method. The VIKOR method has significant similarities with the TOPSIS method, but there are also significant differences, which reflect themselves in the normalization and aggregation phases. For normalization, VIKOR method uses Linear scale transformation, max-min method, or more precisely, aggregation procedure of VIKOR method is also based on the formula (12) and two characteristic metrics, $p=1$ and $p \rightarrow \infty$.

Based on the above, we can state that Compromise programming, similar to the TOPSIS and VIKOR methods, is based on the idea that the best alternative has least distance to the reference point, i.e. ideal solution. However, Compromise programming has much simpler aggregation procedure, which is derived based on well-known Minkowski metric.

It is also significant that the aggregation procedure used in Compromise Programming method, expressed by the formula (12), for $p=1$ has a similar form as the aggregation procedure in the SAW method when Linear transformation max-min method is applied. Also, for $p \rightarrow \infty$ aggregation procedure has great similarities with procedures used in the Reference Point Approach method of the MOORA method.

Finally, compared with COPRAS method, we can conclude that these MCDM methods use aggregation procedures which have approximately same complexity, but their approaches to determine the most appropriate alternative are different.

The Compromise programming methodology has made a prominent use in the field of water resources management (e.g., Duckstein, Opricovic 1980; Simonovic, Burn 1989; Simonovic et al.1992), but it is also applied in many other fields, such as forest management (Tecle et al. 1998; Poff et al. 2010) and economy (Andre et al. 2008).

Ordinary MCDM methods are based on the use of crisp values, and they are not appropriate for solving some complex decision making problems. Therefore, a many ordinary MCDM methods are also extended for use of interval grey numbers. Some proposed extensions of ordinary MCDM methods are: Grey TOPSIS (Zavadskas et al. 2010b; Lin et al. 2008; Chen, Tzeng 2004), Grey AHP (Li et al. 2010), COPRAS-G (Zavadskas et al. 2008a, Zavadskas et al. 2009a), ARAS-G (Turskis, Zavadskas 2010) and SAW-G (Zavadskas et al. 2010b; Medineckiene et al. 2010).

These extended MCDM methods are applied to solve many real world problems, such as material selection (Chatterjee, Chakraborty 2012), cutting tool material selection (Maity et. al 2012), evaluate service quality (Kuo, Liang 2011), selection of project managers (Zavadskas et al. 2008b), selection of an expatriate host country (Chen, Tzeng 2004), and so on.

Also, there are extensions of Compromise programming for use gray numbers. Some of the most prominent are proposed by Luo et al. (2006), Wu and Chang (2004) and Chang et al. (1999).

However, in comparison with other actual MCDM methods, such as TOPSIS, AHP and VIKOR, Compromise programming is rarely used. Therefore, in this article we consider the use of a Compromise programming because of it simplicity and efficiency, and also propose a new extension which allows the use of grey numbers. 


\section{Framework for Comminution Circuits Design evaluation}

One model for the evaluation and selection of CCD, using grey Comprommise programming for group decision making, is proposed in this section. The proposed model consists of the following steps:

Step 1: Select the evaluation criteria. To define criteria for selection of CCD, four experts in the field of Mineral Processing are consulted. They were initially identified four basic criteria:

- Costs;

- Time utilization;

- Valuable minerals utilization; and

- Ore adequacy.

Costs. The criterion named Costs is complex criterion because it includes several types of costs. In order to ensure an efficient model for the selection of CCD this criterion is hierarchically decomposed into several sub-criteria. As a result of decomposition the following sub-criteria are obtained: Investment costs, Energy cost, Grinding media costs, and Maintenance costs.

Due to the decomposition of complex criteria Costs, we have the following complete list of evaluation criteria:

$C_{1}$ - Investment costs,

$\boldsymbol{C}_{\mathbf{2}}$ - Energy cost,

$\boldsymbol{C}_{\mathbf{3}}$ - Grinding media costs,

$\boldsymbol{C}_{4}$ - Maintenance costs,

$C_{5}$ - Time utilization,

$\boldsymbol{C}_{6}-$ Valuable minerals utilization, and

$\boldsymbol{C}_{7}$ - Ore adequacy.

Time utilization. A large amount of heavy equipment and installations used for grinding ore are exposed to high loads which causes the necessity for theirs significant maintenance. The various CCD, or more precisely, the equipment that is used in them, requires different time for maintenance. During a maintenance the grinding plants cannot perform a grinding of ore. Therefore the criterion Time Utilization was introduced to represent the ratio between the time that a plant operates and the time used for its maintenance.

Valuable minerals utilization. Many characteristics of milled ore, such as particle size, particles size distribution and the way of splitting the crystal structure of minerals, can have very significant impact to the ratio between quantity of sepearated valuable minerals and quantity of valuable minerals contained in ore. Different CCD, i.e. equipment used in them, could have effect on the separation of valuable components. Bearing in mind this characteristic of different CCD, we introduce new criterion: Valuable minerals utilization in our model. Valuable minerals utilization is the ratio between estimated quantities of extracted valuable minerals andtotal quantity of valuable minerals in units of ore. 
Ore adequacy. Some types of grinding mills, such as the autogenous (AG) and semiautogenous (SAG) mills, may be more suitable for grinding ore with certain characteristics. Therefore the criterion Ore adequacy is introduced, which allows the opportunity for decision makers to express the adequacy of CCD for a given ore.

Step 2: Determine the weights of evaluation criteria. In MCDM, the weights of criteria are very significant. As a result, numerious approaches have been discussed in the literature, such as pairwise comparisons taken from the AHP method, Entropy method and so on. To determine a more realistic weight of criteria, it is often necessary to examine the opinion of several experts, from a given field. In such cases the use of linguistic variables can be very convenient.

Several linguistic scales with a various numbers of elements were proposed in the literature. There was also considered application of different fuzzy distribution forms for quantification of linguistic variables, such as trapezoidal, triangular and interval form. In this approach, we propose the use of linguistic scale with five variables, shown in Table 1.

Table 1. Linguistic scales for a weights of criteria

\begin{tabular}{cc}
\hline Linguistic variable & Corresponding interval grey number \\
\hline Very low $(\mathrm{VL})$ & {$[0.0,0.3]$} \\
\hline Low $(\mathrm{L})$ & {$[0.1,0.5]$} \\
\hline Medium $(\mathrm{M})$ & {$[0.3,0.7]$} \\
\hline High $(\mathrm{H})$ & {$[0.5,0.9]$} \\
\hline Very high $(\mathrm{VH})$ & {$[0.7,1.0]$} \\
\hline
\end{tabular}

Proposed linguistic scale for weights of criteria is based on the scale proposed by Wang and Chang $(1995,2007)$. However, instead of using a triangular fuzzy numbers for expressing appropriate qualitative values of linguistic variables, we propose the use of interval grey numbers.

Suppose that a group has $K$ decision makers, and that interval grey number $\otimes w_{j}^{k}$ represent the weight of $j$-th criterion assessed by $\mathrm{k}$-th evaluator. To integrate the different opinions of decision makers, the following formula is used:

$$
\otimes w_{j}=\frac{1}{K} \sum_{k=1}^{K} \otimes w_{j}^{k},
$$

where $\otimes w_{j}$ is the weight of $j$-th criterion, expressed by interval grey number; $j=1,2$, $\ldots, n ; n$ is number of criteria; $k=1,2, \ldots, K$.

Since the results obtained by using formula (15) are also interval grey numbers, $\otimes w_{j}$ can be more clearly shown as follows:

$$
\otimes w_{j}^{\prime}=\left[\underline{w}_{j}^{\prime}, \bar{w}_{j}^{\prime}\right]
$$


where

$$
\begin{gathered}
\underline{w}_{j}^{\prime}=\frac{1}{K}\left(\underline{w}_{j}^{1}+\underline{w}_{j}^{2}+\ldots+\underline{w}_{j}^{K}\right) \text { and } \\
\bar{w}_{j}^{\prime}=\frac{1}{K}\left(\bar{w}_{j}^{1}+\bar{w}_{j}^{2}+\ldots+\bar{w}_{j}^{K}\right) .
\end{gathered}
$$

In ordinary MCDM, the following condition is usually satisfied:

$$
\sum_{j=1}^{n} w_{j}=1 \text {. }
$$

When we use the grey criteria weights, each weight is limited by its lower and upper bound, that is why we use condition (20) instead condition (19):

$$
\sum_{j=1}^{n}\left(\underline{w}_{j}+\bar{w}_{j}\right) / 2=1 \text {. }
$$

The weights obtained using the formulae (17) and (18) do not satisfy condition (20), and therefore the normalized criteria weights are calculated using the following formula:

where

$$
\otimes w_{j}=\frac{1}{k_{w}} \times \otimes w_{j}^{\prime},
$$

$$
k_{w}=\sum_{l=1}^{n} w_{l}^{m}
$$

and $w_{l}^{m}$ is Whitened Mid Value of $l$-th ctiterion.

Step 3: Construct the grey decision matrix. The next step in the proposed methodology is constructing decision matrix, using a group decision making approach. For decision making problem which involves $m$ alternatives, $n$ criteria and $K$ decision makers, a typical grey multiple criteria group decision making problem can be expressed in matrix format as follows:

$$
\otimes D=\left[\otimes x_{i j}^{k}\right]_{m \times n \times K},
$$

where $\otimes D$ is grey group decision making matrix; $\otimes x_{i j}^{k}$ is grey performance rating of $i$-th alternative to the $j$-th criterion given by $k$-th decision maker; $I=1,2, \ldots, m ; j=1,2$, $\ldots, n ; k=1,2, \ldots, K$.

Linguistic scales with five linguistic variables, shown in Table 2, are also used for assigning grey performance ratings of alternatives. As well as in the case of linguistic scale for weights of criteria, this scale is also based on the scale proposed by Wang and Chang (1995).

Table 2. Linguistic scales for the ratings of alternatives

\begin{tabular}{cc}
\hline Linguistic variable & Corresponding interval grey number \\
\hline Very poor $(\mathrm{VP})$ & {$[0,3]$} \\
\hline Poor $(\mathrm{P})$ & {$[1,5]$} \\
\hline Medium $(\mathrm{F})$ & {$[3,7]$} \\
\hline High $(\mathrm{G})$ & {$[5,9]$} \\
\hline Very high $(\mathrm{VG})$ & {$[7,10]$} \\
\hline
\end{tabular}


The three-dimensional decision matrix, shown in (23), is not suitable to determine overall performance ratings of considered alternatives, and therefore it is transformed into the corresponding two-dimensional decision matrix as follows:

$$
\otimes D=\left[\otimes x_{i j}\right]_{m \times n},
$$

where $\otimes x_{i j}$ is grey performance rating of $i$-th alternative to the $j$-th criterion, and it can be calculated using the following formula:

$$
\otimes x_{i j}=\frac{1}{K} \sum_{k=1}^{K} \otimes x_{i j}^{k} .
$$

Similar to the formula (15), formula (25) can be accurately displayed as follows:

$$
\otimes x_{i j}=\left[\underline{x}_{i j}, \bar{x}_{i j}\right] \text {, }
$$

where

$$
\begin{gathered}
\underline{x}_{j}=\frac{1}{K}\left(\underline{x}_{j}^{1}+\underline{x}_{j}^{2}+\ldots+\underline{x}_{j}^{K}\right) \text { and } \\
\bar{x}_{j}=\frac{1}{K}\left(\bar{x}_{j}^{1}+\bar{x}_{j}^{2}+\ldots+\bar{x}_{j}^{K}\right) .
\end{gathered}
$$

Step 4: Normalize the grey decision matrix. The next step is forming the normalized decision matrix $\otimes R=\left[\otimes r_{i j}\right]_{m \times n}$.

However, before we consider the formula for calculating the normalized grey performance ratings $\otimes r_{i j}$, we will write formula (12) in the form that is suitable for grey compromise programming use, as shown:

where

$$
\min \otimes L_{p, i}=\left\{\sum_{j=1}^{n}\left(\otimes w_{j} \times \otimes r_{i j}\right)^{p}\right\}^{\frac{1}{p}},
$$

$$
\begin{aligned}
& \otimes r_{i j}=\frac{1}{x_{j}^{+}-x_{j}^{-}} \times \otimes d_{i j},
\end{aligned}
$$

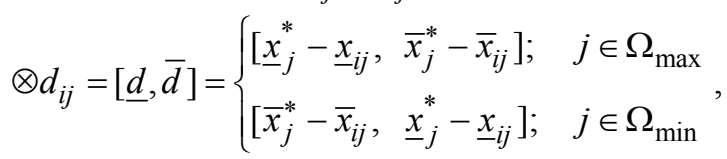

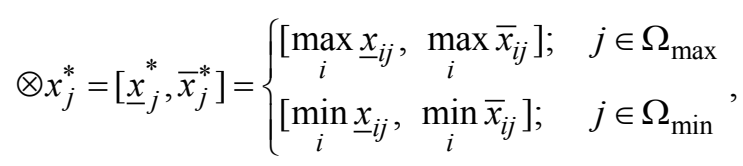

$$
\begin{aligned}
& x_{j}^{+}=\left\{\begin{array}{ll}
\max _{i} \bar{x}_{i j} ; & j \in \Omega_{\max } \\
\min _{i} \underline{x}_{i j} ; & j \in \Omega_{\min }
\end{array}\right. \text { and } \\
& x_{j}^{-}=\left\{\begin{array}{ll}
\min _{i} \underline{x}_{i j} ; & j \in \Omega_{\max } \\
\max _{i} \bar{x}_{i j} ; & j \in \Omega_{\min }
\end{array} .\right.
\end{aligned}
$$


Using formula (30) normalized grey performance ratings can be calculated.

Distance from a grey performance rating to the ideal point is discussed in a detail in Appendix A.

Step 5: Construct the weighted normalized grey decision matrix. Considering different weights of criteria, the weighted normalized decision matrix can be computed by multiplying grey weights of evaluation criteria and the values in the normalized grey decision matrix. The weighted normalized grey decision matrix $\otimes V$ is defined as:

$$
\otimes V=\left[\otimes v_{i j}\right]_{m \times n},
$$

where

$$
\otimes v_{i j}=\otimes w_{j} \cdot \otimes r_{i j}
$$

Step 6: Calculate the grey overall performance rating $\otimes L_{i}$, for each alternative. The overall performance ratings of each alternative, for a given parameter $p$, can be calculated using the following formula:

$$
\otimes L_{i, p}=\left\{\sum_{j=1}^{n} \otimes v_{i j}^{p}\right\}^{\frac{1}{p}},
$$

where $v_{i j}^{p}$ is weighted normalized performance of $i$-th alternative with respect to $j$-th criterion.

As a result of using interval grey numbers in the formula (37), obtained performance rating for each alternative is also interval grey number. To select the most appropriate one, or rank alternatives, it is necessary to translate these interval grey numbers into corresponding crisp numbers, i.e. exact values, and this can be done using formula (10). By using different values of the coefficient $\lambda$, decision maker can examine the different scenarios, from the extremely pessimistic $(\lambda=0)$ to the extremely optimistic $(\lambda=1)$.

Step 7: Determinate the optimal alternative. The applicability of considered alternatives can be determined by sorting their crisp $L_{i}$ in descending order. The most acceptable alternative is the alternative with the lowest value, as shown by the following formula:

$$
A^{*} \in\left\{A_{i}^{*} \mid L=\min _{i} L_{i, p}\right\} \text {. }
$$

\section{Case study and discussion}

In this section we'll show the simplicity and efficiency of the proposed approach in solving particular problem.

The Mining company XYZ from Serbia plans to start exploitation of new mine with surface mining. His geographic location, i.e. the distance of the new mine to the existing flotation, does not provide a cost-effective transportation of excavated ore. Therefore, the team of three experts was formed with the aim to evaluate the comminution circuit design and propose the most appropriate one. They consider three alternatives, i.e. three typical Grinding Circuit designs, as follows: 
Alternative $1\left(A_{1}\right)$ : First typical Comminution circuit design. As first, or typical, we highlight the GCD in which:

i. ore crushing is done in three phases, as primary, secondary and tertiary; and

ii. ore grinding is done in two phases; whereby, the primary grinding is done by using the rod mills, while the secondary grinding is done by using ball mills.

The rod mills usually require less speed versus the similar ball mills, which has a positive effect on energy consumption. A smaller number of rpm is achieved through the use of grinding rods. Furthermore, thanks to the use of rods, a possibility of over-grinding also is reduced. The larger ore particles, formed during primary grinding, are separated using some type of classifiers, usually with hydro-cyclones, and then sent to secondary grinding. In this comminution circuit design, secondary grinding is carried out using ball mills because they allow more efficient grinding of small ore particles. This GCD, shown in Figure 2, provides a high technological efficiency. However, large amount of equipment required in these comminution circuits is associated with a significantly large investment and maintenance costs.

Alternative $2\left(A_{2}\right)$ : Second typical Comminution circuit design. Contrary to previously considered, this GCD, shown in Figure 3, uses one stage grinding process, where the grinding is done using a ball mill.

Alternative $3\left(A_{3}\right)$ : Third typical Comminution circuit design. Third comminution circuit design, shown in Figure 4., is more specific. Its the most important feature is the use of semi-autogenous (SAG) mills, and rarer autogenous (AG) mills.

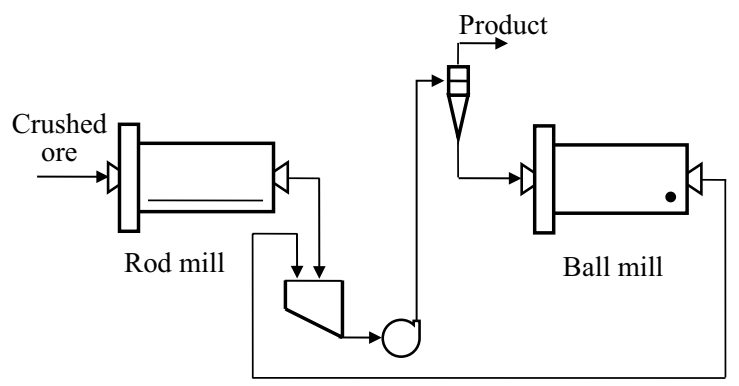

Fig.2. Schematic overview of typically two-stage grinding process, based on the use of rod and ball mills

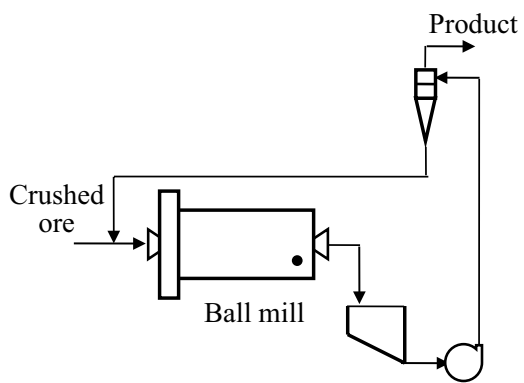

Fig. 3. Schematic overview of onestage grinding process, based on the use of ball mills

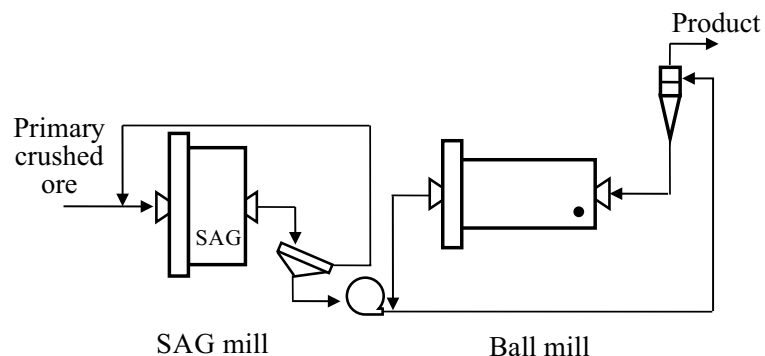

Fig. 4. Schematic overview of two-stage grinding process, based on the use of SAG and ball mills 
Thanks to its characteristics and specificities, these mills are also used for crushing (secondary and tertiary) and grinding (primary). In grinding part this comminution circuit design has similarities with the first GCD.

At the beginning of the evaluation, each expert evaluates the criteria, using the linguistic variables from Table 1. Assigned linguistic variables and the weight of criteria, obtained be using formula (15), or more precisely formulaes (17), (18) and (21), are shown in Table 3.

Table 3. Weights of criteria

\begin{tabular}{lllllc}
\hline \multicolumn{1}{c}{ Criteria } & & $E_{1}$ & $E_{2}$ & $E_{3}$ & $\otimes w_{j}$ \\
\hline Investment costs & $C_{1}$ & $\mathrm{H}$ & $\mathrm{M}$ & $\mathrm{H}$ & {$[0.10,0.19]$} \\
\hline Energy cost & $C_{2}$ & $\mathrm{H}$ & $\mathrm{H}$ & $\mathrm{H}$ & {$[0.12,0.21]$} \\
\hline Grinding media costs & $C_{3}$ & $\mathrm{M}$ & $\mathrm{L}$ & $\mathrm{L}$ & {$[0.04,0.13]$} \\
\hline Maintenance costs & $C_{4}$ & $\mathrm{M}$ & $\mathrm{M}$ & $\mathrm{M}$ & {$[0.07,0.16]$} \\
\hline Time utilization & $C_{5}$ & $\mathrm{H}$ & $\mathrm{M}$ & $\mathrm{M}$ & {$[0.08,0.18]$} \\
\hline Valuable minerals utilization & $C_{6}$ & $\mathrm{VH}$ & $\mathrm{VH}$ & $\mathrm{VH}$ & {$[0.16,0.23]$} \\
\hline Ore adequacy & $C_{7}$ & $\mathrm{H}$ & $\mathrm{H}$ & $\mathrm{H}$ & {$[0.12,0.21]$} \\
\hline
\end{tabular}

In the next step, experts evaluate the performance ratings of considered alternatives to the selected criteria, also using linguistic variables, but now from Table 2. Assigned linguistic variables for performance ratings and corresponding quantitative values, obtained using formula (25), are shown in Table 4.

Table 4. Performance ratings of criteria

\begin{tabular}{cccccc}
\hline Criteria & & $E_{1}$ & $E_{2}$ & $E_{3}$ & $\otimes w_{j}$ \\
\hline$C_{1}$ & $A_{1}$ & $\mathrm{G}$ & $\mathrm{F}$ & $\mathrm{G}$ & {$[4.33,8.33]$} \\
\hline$C_{1}$ & $A_{2}$ & $\mathrm{~F}$ & $\mathrm{P}$ & $\mathrm{F}$ & {$[2.33,6.33]$} \\
\hline$C_{1}$ & $A_{3}$ & $\mathrm{~F}$ & $\mathrm{G}$ & $\mathrm{G}$ & {$[3.67,7.67]$} \\
\hline$C_{2}$ & $A_{1}$ & $\mathrm{G}$ & $\mathrm{G}$ & $\mathrm{G}$ & {$[5.00,9.00]$} \\
\hline$C_{2}$ & $A_{2}$ & $\mathrm{~F}$ & $\mathrm{~F}$ & $\mathrm{~F}$ & {$[3.00,7.00]$} \\
\hline$C_{2}$ & $A_{3}$ & $\mathrm{P}$ & $\mathrm{G}$ & $\mathrm{P}$ & {$[2.33,6.33]$} \\
\hline$C_{3}$ & $A_{1}$ & $\mathrm{G}$ & $\mathrm{G}$ & $\mathrm{G}$ & {$[5.00,9.00]$} \\
\hline$C_{3}$ & $A_{2}$ & $\mathrm{~F}$ & $\mathrm{G}$ & $\mathrm{F}$ & {$[3.67,7.67]$} \\
\hline$C_{3}$ & $A_{3}$ & $\mathrm{P}$ & $\mathrm{F}$ & $\mathrm{P}$ & {$[1.67,5.67]$} \\
\hline$C_{4}$ & $A_{1}$ & $\mathrm{G}$ & $\mathrm{G}$ & $\mathrm{G}$ & {$[5.00,9.00]$} \\
\hline$C_{4}$ & $A_{2}$ & $\mathrm{G}$ & $\mathrm{F}$ & $\mathrm{F}$ & {$[3.67,7.67]$} \\
\hline
\end{tabular}


End of Table 4

\begin{tabular}{cccccc}
\hline Criteria & & $E_{1}$ & $E_{2}$ & $E_{3}$ & $\otimes w_{j}$ \\
\hline$C_{4}$ & $A_{3}$ & $\mathrm{~F}$ & $\mathrm{~F}$ & $\mathrm{~F}$ & {$[3.00,7.00]$} \\
\hline$C_{5}$ & $A_{1}$ & $\mathrm{~F}$ & $\mathrm{~F}$ & $\mathrm{G}$ & {$[3.67,7.67]$} \\
\hline$C_{5}$ & $A_{2}$ & $\mathrm{G}$ & $\mathrm{F}$ & $\mathrm{F}$ & {$[3.67,7.67]$} \\
\hline$C_{5}$ & $A_{3}$ & $\mathrm{G}$ & $\mathrm{F}$ & $\mathrm{VG}$ & {$[5.00,8.67]$} \\
\hline$C_{6}$ & $A_{1}$ & $\mathrm{G}$ & $\mathrm{VG}$ & $\mathrm{G}$ & {$[5.67,9.33]$} \\
\hline$C_{6}$ & $A_{2}$ & $\mathrm{~F}$ & $\mathrm{VG}$ & $\mathrm{F}$ & {$[4.33,8.00]$} \\
\hline$C_{6}$ & $A_{3}$ & $\mathrm{VG}$ & $\mathrm{VG}$ & $\mathrm{G}$ & {$[7.00,10.0]$} \\
\hline$C_{7}$ & $A_{1}$ & $\mathrm{VG}$ & $\mathrm{VG}$ & $\mathrm{VG}$ & {$[7.00,10.0]$} \\
\hline$C_{7}$ & $A_{2}$ & $\mathrm{~F}$ & $\mathrm{~F}$ & $\mathrm{G}$ & {$[3.67,7.67]$} \\
\hline$C_{7}$ & $A_{3}$ & $\mathrm{G}$ & $\mathrm{F}$ & $\mathrm{VG}$ & {$[5.00,8.67]$} \\
\hline
\end{tabular}

Based on the data shown in Tables 4 and 3 a grey decision matrix, shown in Table 5, is formed.

Table 5. Grey decision matrix

\begin{tabular}{cccccccc}
\hline & $C_{1}$ & $C_{2}$ & $C_{3}$ & $C_{4}$ & $C_{5}$ & $C_{6}$ & $C_{7}$ \\
\hline$w_{j}$ & {$[0.10,0.19]$} & {$[0.12,0.21]$} & {$[0.04,0.13]$} & {$[0.07,0.16]$} & {$[0.08,0.18]$} & {$[0.16,0.23]$} & {$[0.12,0.21]$} \\
\hline Opt. & $\min$ & $\min$ & $\min$ & $\min$ & $\max$ & $\max$ & $\max$ \\
\hline$A_{1}$ & {$[4.33,8.33]$} & {$[5.00,9.00]$} & {$[5.00,9.00]$} & {$[5.00,9.00]$} & {$[3.67,7.67]$} & {$[5.67,9.33]$} & {$[7.00,10.0]$} \\
\hline$A_{2}$ & {$[2.33,6.33]$} & {$[3.00,7.00]$} & {$[3.67,7.67]$} & {$[3.67,7.67]$} & {$[3.67,7.67]$} & {$[4.33,8.00]$} & {$[3.67,7.67]$} \\
\hline$A_{3}$ & {$[3.67,7.67]$} & {$[2.33,6.33]$} & {$[1.67,5.67]$} & {$[3.00,7.00]$} & {$[5.00,8.67]$} & {$[7.00,10.0]$} & {$[5.00,8.67]$} \\
\hline
\end{tabular}

The grey ideal point $\otimes x_{j}^{*}$, the largest $x_{j}^{+}$and the smallest $x_{j}^{-}$performance ratings, for any criterion, are determined using the formulae (32), (33) and (34), and these values are shown in Table 6.

Table 6. The grey ideal point and largest and smallest performance ratings

\begin{tabular}{cccccccc}
\hline & $C_{1}$ & $C_{2}$ & $C_{3}$ & $C_{4}$ & $C_{5}$ & $C_{6}$ & $C_{7}$ \\
\hline Opt. & $\min$ & $\min$ & $\min$ & $\min$ & $\max$ & $\max$ & $\max$ \\
\hline$\otimes x_{j}^{*}$ & {$[2.33,6.33]$} & {$[2.33,6.33]$} & {$[1.67,5.67]$} & {$[3.00,7.00]$} & {$[5.00,8.67]$} & {$[7.00,10.0]$} & {$[7.00,10.0]$} \\
\hline$x_{j}^{+}$ & 2.33 & 2.33 & 1.67 & 3.00 & 8.67 & 10.00 & 10.00 \\
\hline$x_{j}^{-}$ & 8.33 & 9.00 & 9.00 & 9.00 & 3.67 & 4.33 & 3.67 \\
\hline
\end{tabular}

Based on data from Tables 5 and 6, distances from alternatives to the grey ideal point are calculated using the formula (31). These distances are shown in Table 7. 
Table 7. Distances from alternatives to the grey ideal point, in relation to the evaluation criteria

\begin{tabular}{cccccccc}
\hline & $C_{1}$ & $C_{2}$ & $C_{3}$ & $C_{4}$ & $C_{5}$ & $C_{6}$ & $C_{7}$ \\
\hline Opt. & $\min$ & $\min$ & $\min$ & $\min$ & $\max$ & $\max$ & $\max$ \\
\hline$A_{1}$ & {$[-2.00,-2.00]$} & {$[-2.67,-2.67][-3.33,-3.33][-2.00,-2.00]$} & {$[1.33,1.00]$} & {$[1.33,0.67]$} & {$[0.00,0.00]$} \\
\hline$A_{2}$ & {$[0.00,0.00]$} & {$[-0.67,-0.67][-2.00,-2.00][-0.67,-0.67]$} & {$[1.33,1.00]$} & {$[2.67,2.00]$} & {$[3.33,2.33]$} \\
\hline$A_{3}$ & {$[-1.33,-1.33]$} & {$[0.00,0.00]$} & {$[0.00,0.00]$} & {$[0.00,0.00]$} & {$[0.00,0.00]$} & {$[0.00,0.00]$} & {$[2.00,1.33]$} \\
\hline
\end{tabular}

After that, using the formula (30) normalized grey decision matrix was formed. The normalized grey decision matrix is shown in Table 8 .

Table 8. Normalized grey decision matrix

\begin{tabular}{cccccccc}
\hline & $C_{1}$ & $C_{2}$ & $C_{3}$ & $C_{4}$ & $C_{5}$ & $C_{6}$ & $C_{7}$ \\
\hline Opt. & $\min$ & $\min$ & $\min$ & $\min$ & $\max$ & $\max$ & $\max$ \\
\hline$A_{1}$ & {$[0.33,0.33]$} & {$[0.40,0.40]$} & {$[0.45,0.45]$} & {$[0.33,0.33]$} & {$[0.27,0.20]$} & {$[0.24,0.12]$} & {$[0.00,0.00]$} \\
\hline$A_{2}$ & {$[0.00,0.00]$} & {$[0.10,0.10]$} & {$[0.27,0.27]$} & {$[0.11,0.11]$} & {$[0.27,0.20]$} & {$[0.47,0.35]$} & {$[0.53,0.37]$} \\
\hline$A_{3}$ & {$[0.22,0.22]$} & {$[0.00,0.00]$} & {$[0.00,0.00]$} & {$[0.00,0.00]$} & {$[0.00,0.00]$} & {$[0.00,0.00]$} & {$[0.32,0.21]$} \\
\hline
\end{tabular}

In the next step, using the formula (30), the weighted normalized grey decision matrix was formed, and it is shown in Table 9.

Table 9. Weighted normalized grey decision matrix

\begin{tabular}{cccccccc}
\hline & $C_{1}$ & $C_{2}$ & $C_{3}$ & $C_{4}$ & $C_{5}$ & $C_{6}$ & $C_{7}$ \\
\hline Opt. & $\min$ & $\min$ & $\min$ & $\min$ & $\max$ & $\max$ & $\max$ \\
\hline$A_{1}$ & {$[0.03,0.06]$} & {$[0.05,0.08]$} & {$[0.02,0.06]$} & {$[0.02,0.05]$} & {$[0.02,0.04]$} & {$[0.04,0.03]$} & {$[0.00,0.00]$} \\
\hline$A_{2}$ & {$[0.00,0.00]$} & {$[0.01,0.02]$} & {$[0.01,0.04]$} & {$[0.01,0.02]$} & {$[0.02,0.04]$} & {$[0.08,0.08]$} & {$[0.06,0.08]$} \\
\hline$A_{3}$ & {$[0.02,0.04]$} & {$[0.00,0.00]$} & {$[0.00,0.00]$} & {$[0.00,0.00]$} & {$[0.00,0.00]$} & {$[0.00,0.00]$} & {$[0.04,0.04]$} \\
\hline
\end{tabular}

Finally, using the formula (37), and different values for the parameter $p$, decision makers can determine the ranking of alternatives and selection of the most appropriate one. Also, using different values of the coefficient $\lambda$ decision makers can examine different scenarios, such as pessimistic, moderate or optimistic.

The ranking results obtained using formula (37) for $p=1$ and some characteristic values of coefficient $\lambda$, are shown in Table 10 .

As can be seen, for different values of the coefficient $\lambda$, alternative $A_{3}$ is the best placed. Depending on the value of $\lambda$ alternatives $A_{1}$ and $A_{2}$ have the second or third position. Obtained results were expected, however the high dominance of alternative $A_{3}$ is in a way surprising. The explanation lies in the fact that three experts from the field of mineral processing was involved in this evaluation, and they gave more importance to criteria which are related to technology and utilization of valuable minerals from ore. 
Table 10. Ranking results obtained for $p=1$ and characteristic values of $\lambda$

\begin{tabular}{cccccccc}
\hline & & \multicolumn{2}{c}{$\lambda=0$} & \multicolumn{2}{c}{$\lambda=0.5$} & \multicolumn{2}{c}{$\lambda=1$} \\
\hline & $\otimes L_{i}$ & $L_{i}$ & Rank & $L_{i}$ & Rank & $L_{i}$ & Rank \\
\hline$A_{1}$ & {$[0.181,0.324]$} & 0.181 & 2 & 0.253 & 3 & 0.324 & 3 \\
\hline$A_{2}$ & {$[0.190,0.269]$} & 0.190 & 3 & 0.229 & 2 & 0.269 & 2 \\
\hline$A_{3}$ & {$[0.059,0.087]$} & 0.059 & 1 & 0.073 & 1 & 0.087 & 1 \\
\hline
\end{tabular}

Analysis of obtained criteria weights fully confirms the above statement. For example, the criterion $C_{6}-$ Valuable minerals utilization is given more importance $[0.16,0.23]$ compared to the criterion $C_{1}$ - Investment costs, which has a weight of $[0.10,0.19]$.

By including a financial expert in the process of determining the weight of criteria, we would probably get the other weight of criteria.

However, limited amounts of minerals no longer allow their irrational exploitation. In addition, the higher time utilization and higher utilization of valuable minerals in the long run provides better financial results.

Table 11 shows the width $\otimes x_{\omega}$ and the grey degree $G d(\otimes x)$ of the overall grey performance ratings of the considered alternatives. As can be seen, the alternative $A_{3}$ has very small width and grey degree over other alternatives, which make it as the most appropriate alternative.

Table 11. The width and grey degree of overall grey performance ratings

\begin{tabular}{ccccc}
\hline & $\otimes L_{i}$ & $\otimes x_{\omega}$ & $\mathrm{x}_{\mathrm{m}}$ & $\mathrm{Gd}$ \\
\hline$A_{1}$ & {$[0.181,0.324]$} & 0.273 & 0.186 & 146.87 \\
\hline$A_{2}$ & {$[0.190,0.269]$} & 0.242 & 0.173 & 139.68 \\
\hline$A_{3}$ & {$[0.059,0.087]$} & 0.002 & 0.193 & 0.98 \\
\hline
\end{tabular}

The ranking results obtained using formula (37) for $p=2$ and some characteristic values of coefficient $\lambda$, are shown in Table 12. For $p=2$ the city-block distance is replaced with Euclidean distance, which is used in very prominent TOPSIS method, but the TOPSIS also includes the distance between alternative and anti-ideal solution, and uses a different normalization procedure.

Table 12. Ranking results obtained using proposed approach for $p=2$ and characteristic values of coefficient $\lambda$

\begin{tabular}{cccccccc}
\hline & & \multicolumn{2}{c}{$\lambda=0$} & \multicolumn{2}{c}{$\lambda=0.5$} & \multicolumn{2}{c}{$\lambda=1$} \\
\hline & $\otimes L_{i}$ & $L_{i}$ & Rank & $L_{i}$ & Rank & $L_{i}$ & Rank \\
\hline$A_{1}$ & {$[0.033,0.105]$} & 0.033 & 2 & 0.069 & 3 & 0.105 & 3 \\
\hline$A_{2}$ & {$[0.036,0.072]$} & 0.036 & 3 & 0.054 & 2 & 0.072 & 2 \\
\hline$A_{3}$ & {$[0.003,0.008]$} & 0.003 & 1 & 0.006 & 1 & 0.008 & 1 \\
\hline
\end{tabular}


The parameter $p$ is used in formulas (12) and (29) to represent the importance of the maximal deviation from the ideal solution, i.e. distance between an alterative an ideal solution. When $p=1$ all deviations have equal importance, but with increasing value of the parameter $p$ also increases an importance of larger deviations, so that when $p \rightarrow \infty$ impact to the rank order of alternatives have only their largest deviations.

By using $p=2$ and the decision makers moderate attitude, the alternative $A_{3}$ becomes the best placed, while in case of its pessimistic and optimistic attitude takes the second position.

According to the opinion of experts who were involved in the ranking, this rank order is most acceptable.

\section{Conclusions}

Comminution circuit design selection is very important and also very complex problem. In order to select the most appropriate comminution circuit design, it is necessary to include the impact of a number of conflicting criteria.

However, this problem is too complex and does not allow to express performance ratings of alternatives using crisp numbers, which is why we propose the use of interval grey numbers.

We also believe that the complexity of the proposed MCDM methods has an impact on their acceptance by decision makers. Therefore we selected one simple MCDM method and proposed its extension in order to use interval grey numbers. Although it is based on a simple procedure, we consider that the proposed model is efficient and flexible, and that it also represents the basis for forming more sophisticated models for comminution circuit design selection.

The ordinary Compromise Programming method lie between simplicity of Simple additive weighting method and reliability of the TOPSIS method.

We hope that the proposed extension of Compromise Programming will keep the same performances, simplicity and reliability, with additional flexibility in solving real world problems obtained on the basis of interval grey numbers use.

We also believe that it can be used much broader, for modeling and solving complex real-world decision problems in business environments, especially a category of decision problems related with predictions and uncertainties.

\section{Acknowledgements}

This paper is a partial result of the project TR33023 financed by the Ministry of Science and Technological Development of the Republic of Serbia.

\section{References}

Ahmadabadi, A. D.; Pourkarimi, Z.; Noaparast, M.; Shafaei, S. Z.; Jorjani, E. 2008. Evaluation of grinding circuit performance in Esfordi phosphate processing plant, Iranian Journal of Science \& Technology, Transaction B, Engineering 32(4): 415-424. 
Andre, F. J.; Cardenete, M. A.; Romero, C. 2008. Using compromise programming for macroeconomic policy making in a general equilibrium framework: theory andapplication to the Spanish economy, Journal of the Operational Research Society 59(1): 875-883.

http://dx.doi.org/10.1057/palgrave.jors.2602415

Bellman, R. E.; Zadeh, L. A. 1970. Decision-making in a fuzzy environment, Management Science 17(4): 141-164. http://dx.doi.org/10.1287/mnsc.17.4.B141

Brans, J. P.; Vincke, P. 1985. A preference ranking organization method: the PROMETHEE method for MCDM, Management Science 31(6): 647-656. http://dx.doi.org/10.1287/mnsc.31.6.647v

Brauers, W. K. M; Zavadskas, E. K. 2006. The MOORA method and its application to privatization in a transition economy, Control and Cybernetics 35(2): 445-469.

Chang, N. B.; Yeh, S. C.; Wu, G. C. 1999. Stability analysis of grey compromise programming and its application to watershed land-use planning, International Journal of Systems Science 30(6): 571-589. http://dx.doi.org/10.1080/002077299292092

Chatterjee, P.; Chakraborty, S. 2012. Material selection using preferential ranking methods, $M a-$ terials and Design 35: 384-393. http://dx.doi.org/10.1016/j.matdes.2011.09.027

Chen, M. F.; Tzeng, G. H. 2004. Combining grey relation and TOPSIS concepts for selecting an expatriate host country, Mathematical and Computer Modeling 40(13): 1473-1490.

http://dx.doi.org/10.1016/j.mcm.2005.01.006

Deng, J. L. 1982. Control problems of grey systems, System Control Letters 11(5): 211-5.

Deng, J. L. 1989. Introduction to Grey System Theory, Journal of Grey Systems 1(1): 1-24.

Deng, J. L. 1992. An introduction to Grey Mathematics - Grey Hazy Set. Wuhan: Press of Huazhong University of Science and Technology.

Duckstein, L; Opricovic, S. 1980. Multiobjective optimization in river basin development, Water Resources Research 16(1): 14-20. http://dx.doi.org/10.1029/WR016i001p00014

Ergun, L.; Ekmekci, Z.; Gulsoy, O.; Benzer, H. 2004. Modelling and simulation of grinding circuit in Madneuli copper concentrator, Physicochemical Problems of Mineral Processing 38(1): 231-240.

Huang, G. H.; Baetz B. W.; Patry G. G. 1995. Grey integer programming: an application to waste management planning under uncertainty, European Journal of Operational Research 83(1): 594-620. http://dx.doi.org/10.1016/0377-2217(94)00093-R

Hwang, C. L.; Yoon, K. 1981. Multiple attribute decision making: methods and applications. New York: Springer. http://dx.doi.org/10.1007/978-3-642-48318-9

Kuo, M. S.; Liang G. S. 2011. Combining VIKOR with GRA techniques to evaluate service quality of airports under fuzzy environment, Expert Systems with Application 38(3): 1304-1312. http://dx.doi.org/10.1016/j.eswa.2010.07.003

Li, Y.; Suo, J.; Zhou, S. 2010. A novel assessment based on grey AHP, Applied Mechanics and Materials 26-28(1): 269-272. http://dx.doi.org/10.4028/www.scientific.net/AMM.26-28.269

Lin, Y. H.; Lee, P. C.; Chang, T. P.; Ting, H. I. 2008. Multi-attribute group decision making model under the condition of uncertain information, Automation in Construction 17(6): 792-797. http://dx.doi.org/10.1016/j.autcon.2008.02.011

Liu, S. F.; Lin, Y. 2006. Grey information: theory and practical applications. London: Springer.

Luo, Z.; Chen, L. P.; Yang, J. Z.; Zhang, Y. Q. 2006. Multiple stiffness topology optimizations of continuum structures, International journal of advanced manufacturing technology 30(3-4): 203-214. http://dx.doi.org/10.1007/s00170-005-0084-z

MacCrimon, K. R. 1968. Decision marking among multiple-attribute alternatives: a survey and consolidated approach. RAND memorandum, RM-4823-ARPA. Santa Monica, California: The Rand Corporation. 
Maity, S. R.; Chatterjee, P; Chakraborty, S. 2012. Cutting tool material selection using grey complex proportional assessment method, Material and Design 36: 372-378.

http://dx.doi.org/10.1016/j.matdes.2011.11.044

Medineckiene, M.; Turskis, Z.; Zavadskas, E. K. 2010. Sustainable construction taking into account the building impact on the environment, Journal of Environmental Engineering and Landscape Management 18(2): 118-127. http://dx.doi.org/10.3846/jeelm.2010.14

Opricovic, S. 1998. Visekriterijumska optimizacija u građevinarstvu [Multi-criteria optimization of civil engineering systems]. Faculty of Civil Engineering, Belgrade.

Poff, B.; Tecle, A.; Neary, D. G.; Geils, B. 2010. Compromise programming in forest management, Journal of the Arizona-Nevada Academy of Science 42(1): 44-60.

http://dx.doi.org/10.2181/036.042.0107

Putland, B. 2006. Comminution circuit selection - key drivers and circuit limitations. Department of Mining Engineering University of British Columbia, Vancouver, B. C., Canada.

Roy, B. 1991. The Outranking Approach and the Foundation of ELECTRE Methods, Theory and Decision 31(1): 49-73. http://dx.doi.org/10.1007/BF00134132

Saaty, T. L. 1980. Analytic hierarchy process: planning, priority setting, resource allocation. McGraw-Hill, New York.

Simonovic, S. P.; Burn, D. H. 1989. An improved methodology for short-term operation of a single multipurpose reservoir, Water Resources Research 25(1): 1-8.

http://dx.doi.org/10.1029/WR025i001p00001

Simonovic, S. P.; Venema, H. D.; Burn, D. H. 1992. Risk-based parameter selection for shortterm reservoir operation, Journal of Hydrology 131(1): 269-291.

http://dx.doi.org/10.1016/0022-1694(92)90222-H

Stanujkic, D.; Magdalinovic, N.; Jovanovic, R.; Stojanovic, S. 2012. An objective multi-criteria approach to optimization using MOORA method and interval grey numbers, Technological and Economic Development of Economy 18(2): 331-363.

http://dx.doi.org/10.3846/20294913.2012.676996

Tecle, A.; Shrestha, B. P.; Duckstein, L. 1998. A multiobjective decision support system for multiresource forest management, Group Decision and Negotiation 7(1): 23-40.

http://dx.doi.org/10.1023/A:1008671129325

Turskis, Z.; Zavadskas, E. K. 2010. A novel method for multiple criteria analysis: Grey additive ratio assessment (ARAS-G) method, Informatica 21(4): 597-610.

Wang, M. J.; Chang, T. C. 1995. Tool steel materials selection under fuzzy environment, Fuzzy Sets and Systems 72(3): 263-270. http://dx.doi.org/10.1016/0165-0114(94)00289-J

Wang, T. C; Chang, T. H. 2007. Application of TOPSIS in evaluating initial training aircraft under a fuzzy environment, Expert Systems with Applications 33(4): 870-880.

http://dx.doi.org/10.1016/j.eswa.2006.07.003

Wu, C. C.; Chang, N. B. 2004. Corporate optimal production planning with varying environmental costs: a grey compromise programming approach, European Journal of Operational Research 155(1): 68-95. http://dx.doi.org/10.1016/S0377-2217(02)00820-2

Yu, P. L. 1973. A class of solutions for group decision problems, Management Science 19(8): 936-946. http://dx.doi.org/10.1287/mnsc.19.8.936

Zadeh, L. A. 1965. Fuzzy sets, Information and Control 8(1): 338-353.

http://dx.doi.org/10.1016/S0019-9958(65)90241-X

Zavadskas, E. K.; Kaklauskas, A.; Sarka, V. 1994. The new method of multicriteria complex proportional assessment of projects, Technological and Economic Development of Economy 1(3): $131-139$. 
Zavadskas, E. K.; Kaklauskas, A.; Turskis, Z.; Tamosaitiene, J. 2008a. Selection of the effective dwelling house walls by applying attributes values determined at intervals, Journal of Civil Engineering and Management 14(2): 85-93.

Zavadskas, E. K.; Kaklauskas, A.; Turskis, Z.; Tamosaitiene, J. 2009a. Multi-Attribute DecisionMaking model by applying grey numbers, Informatica 20(2): 305-320.

Zavadskas, E. K.; Kaklauskas, A.; Vilutiene, T. 2009b. Multicriteria evaluation of apartment blocks maintenance contractors: Lithuanian case study, International Journal of Strategic Property Management 13(4): 319-338. http://dx.doi.org/10.3846/1648-715X.2009.13.319-338

Zavadskas, E. K.; Turskis, Z. 2010. A new additive ratio assessment (ARAS) method in multicriteria decision-making, Technological and Economic Development of Economy 16(2): 159-172. http://dx.doi.org/10.3846/tede.2010.10

Zavadskas, E. K.; Turskis, Z.; Tamosaitiene, J.; Marina, V. 2008b. Multicriteria selection of project managers by applying Grey criteria, Technological and Economic Development of Economy 14(4): 462-477. http://dx.doi.org/10.3846/1392-8619.2008.14.462-477

Zavadskas, E. K.; Turskis, Z.; Vilutiene, T. 2010a. Multiple criteria analysis of foundation instalment alternatives by applying Additive Ratio Assessment (ARAS) method, Archives of Civil and Mechanical Engineering 10(3): 123-141.

Zavadskas, E. K.; Vilutiene, T.; Turskis, Z.; Tamosaitiene, J. 2010b. Contractor selection for construction works by applying SAW-G and TOPSIS grey techniques, Journal of Business Economics and Management 11(1): 34-55.

Zeleny, M. 1973. Compromise programming, in J. Cochrane L. \& M. Zeleny (Eds.). Multiple criteria decision making. Columbia, SC: University of South Carolina Press, 262-301.

\section{APPENDIX}

\section{How to measure the distance between an interval grey number and the ideal point?}

The procedure for determining the distance between an interval grey number and reference point is more complex than the procedure used for determining distance between a crisp number and reference point and it initiates three dilemmas (Stanujkic et al. 2012). The first dilemma is which characteristic of an interval grey number best represents the interval grey number: its upper or lower bound, mean, or another characteristic? The second dilemma is how to determine the ideal point when performance ratings are expressed using interval grey numbers? This dilemma also initiates the third, very important, dilemma: What is really ideal point in cases of using interval grey numbers? Just crisp point in n-dimensional space or grey reference point, i.e. grey body - ellipsoid, in n-dimensional space (Stanujkic et al. 2012)?

Figure 5, adopted from Stanujkic et al. 2012, shows three characteristic reference point theory approaches. The first approach (a) shows distance between a point (an exact value) to the reference point. Next approach (b) shows the distance between an interval grey number and classical reference point, and the last approach (c) shows distance between interval grey number and the grey ideal point.

In the multiple criteria decision making we must accept the fact that there are, if we omit the rare non-monotonic, two types of criteria: the cost and benefit criteria. 
When we use the grey interval numbers to determine the performance ratings of benefit criteria, intervals upper bounds reflect optimistic and intervals lower bounds reflect pessimistic decision makers point of view. In contrary to the previous one, when we consider cost criteria, intervals lower bounds reflect optimistic and intervals upper bounds reflect pessimistic point of view. Figure 6 shows distances between the grey performance rating and crisp ideal point.

To determine the ideal point in the considered case, we can use the following formula:

$$
x_{j}^{*}=\left\{\begin{array}{ll}
\max _{i} \underline{x}_{i j} ; & j \in \Omega_{\max } \\
\min _{i} \underline{x}_{i j} ; & j \in \Omega_{\min }
\end{array},\right.
$$

when observed in n-dimensional space, the ideal point is a point whose coordinate on the $j$-th axis represents the most desirable performance $j$-th criterion.

After that, the most desirable $d_{j}^{+}$and least desirable $d_{j}^{-}$distance between the grey reference point and ideal point can be calculated using following formula:

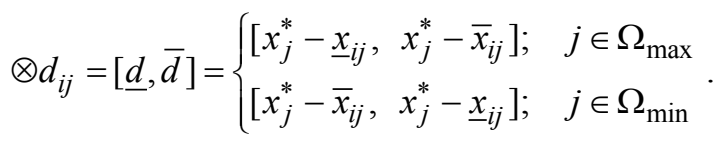

However, when we use the interval grey numbers to represent performance ratings, we also prefer to use it to represent the most desirable performance ratings of criteria, and thus for presenting coordinates of grey ideal point.

We use the formula (32) to determine the coordinates of the grey ideal point and formula (31) to determine the distances between the grey performance rating and the grey ideal point. Figure 7 shows distances between the grey performance rating and grey ideal point.

a)

b)

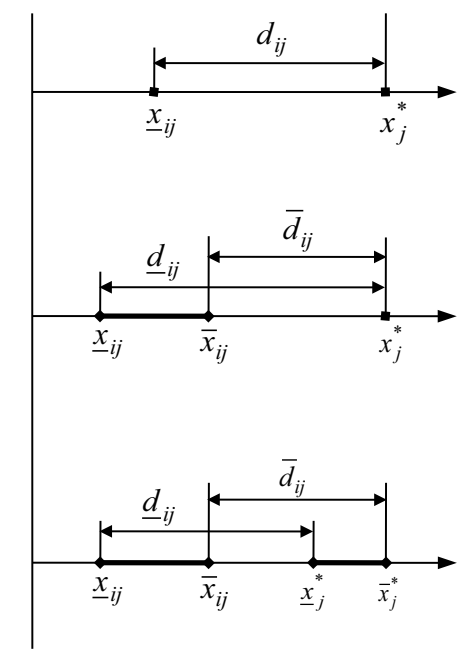

Fig. 5. Characteristic reference point approaches

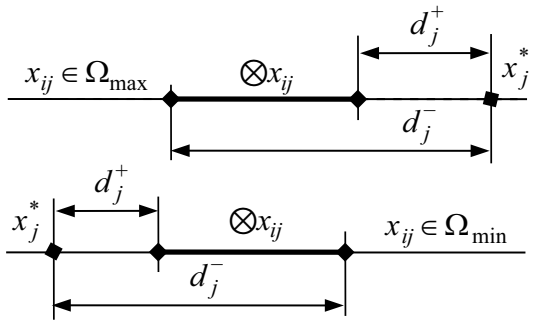

Fig. 6. The distances between the grey performance rating and crisp ideal point

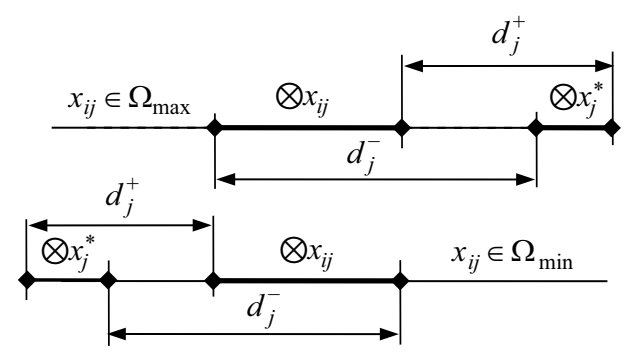

Fig. 7. The distances between the grey performance rating and grey ideal point 
In the example below, a comparison of the previously discussed approach is shown. Let it be given five alternatives $A_{1}, A_{2}, \ldots, A_{5}$, which is evaluated with respect to two criteria, $C_{1}$ and $C_{2}$. The data needed for their evaluation are given in Table 13 .

Table 13. The data used for the evaluation of alternatives

\begin{tabular}{cccccc}
\hline & \multicolumn{5}{c}{ Criteria } \\
\hline Weight & 0.50 & & 0.50 & 0.50 & $C_{2}$ \\
\hline Optimization & & min & & \multicolumn{2}{c}{ max } \\
\hline Alternatives & $\underline{x}_{1 j}$ & $\bar{x}_{1 j}$ & $\underline{x}_{2 j}$ & $\bar{x}_{2 j}$ \\
\hline$A_{1}$ & 45 & 55 & 45 & 55 \\
\hline$A_{2}$ & 50 & 65 & 50 & 65 \\
\hline$A_{3}$ & 25 & 45 & 25 & 45 \\
\hline$A_{4}$ & 65 & 90 & 65 & 90 \\
\hline$A_{5}$ & 10 & 40 & 10 & 40 \\
\hline
\end{tabular}

Data obtained using the formula (39) and (40), as well as appropriate distance metrics for $p=1$, are shown in Table 14. Table 15 shows the results of ranking the alternatives for the characteristic values of $\lambda$.

Table 14. The results of calculations in the case of crisp ideal point

\begin{tabular}{|c|c|c|c|c|c|c|c|}
\hline & \multicolumn{2}{|c|}{$\otimes x_{i j}$} & \multicolumn{2}{|c|}{$\otimes d_{i i}$} & \multicolumn{2}{|c|}{$\otimes r_{i j}$} & \multirow{2}{*}{$\otimes L_{1, i}$} \\
\hline & $C_{2}$ & $C_{1}$ & $C_{2}$ & $C_{2}$ & $C_{1}$ & $C_{2}$ & \\
\hline$A_{1}$ & {$[45,55]$} & {$[45,55]$} & {$[-45,-35]$} & {$[45,35]$} & {$[0.56,0.44]$} & {$[0.56,0.44]$} & {$[0.56,0.44]$} \\
\hline$A_{2}$ & {$[50,65]$} & {$[50,65]$} & {$[-55,-40]$} & {$[40,25]$} & {$[0.69,0.50]$} & {$[0.50,0.31]$} & {$[0.59,0.41]$} \\
\hline$A_{3}$ & {$[25,45]$} & {$[25,45]$} & {$[-35,-15]$} & {$[65,45]$} & {$[0.44,0.19]$} & {$[0.81,0.56]$} & {$[0.63,0.38]$} \\
\hline$A_{4}$ & {$[65,90]$} & {$[65,90]$} & {$[-80,-55]$} & {$[25,0]$} & {$[1.00,0.69]$} & {$[0.31,0.00]$} & {$[0.66,0.34]$} \\
\hline$A_{5}$ & {$[10,40]$} & {$[10,40]$} & {$[-30,0]$} & {$[80,50]$} & {$[0.38,0.00]$} & {$[1.00,0.63]$} & {$[0.69,0.31]$} \\
\hline
\end{tabular}

Table 15. The ranking results in the case of crisp ideal point

\begin{tabular}{cccccccc}
\hline & & \multicolumn{2}{c}{$\lambda=0$} & \multicolumn{2}{c}{$\lambda=0.5$} & \multicolumn{2}{c}{$\lambda=1$} \\
\hline & $\otimes L_{1, i}$ & $L_{i}$ & Rank & $L_{i}$ & Rank & $L_{i}$ & Rank \\
\hline$A_{1}$ & {$[0.56,0.44]$} & 0.56 & 1 & 0.5 & 1 & 0.44 & 5 \\
\hline$A_{2}$ & {$[0.59,0.41]$} & 0.59 & 2 & 0.5 & 1 & 0.41 & 4 \\
\hline$A_{3}$ & {$[0.63,0.38]$} & 0.63 & 3 & 0.5 & 1 & 0.38 & 3 \\
\hline$A_{4}$ & {$[0.66,0.34]$} & 0.66 & 4 & 0.5 & 1 & 0.34 & 2 \\
\hline$A_{5}$ & {$[0.69,0.31]$} & 0.69 & 5 & 0.5 & 1 & 0.31 & 1 \\
\hline
\end{tabular}


Data obtained using the formula (32) and (31), as well as appropriate distance metrics for $p=1$, are shown in Table 16. Table 17 shows the results of ranking alternatives for the characteristic values of $\lambda$.

Table 16. The results of calculations in the case of grey ideal point

\begin{tabular}{|c|c|c|c|c|c|c|c|}
\hline \multicolumn{3}{|c|}{$\otimes x_{\mathrm{i}}$} & \multicolumn{2}{|c|}{$\otimes d_{\mathrm{i}}$} & \multicolumn{2}{|c|}{$\otimes r_{\mathrm{i}}$} & \multirow{2}{*}{$\otimes L_{1, i}$} \\
\hline & $C_{1}$ & $C_{2}$ & $C_{1}$ & $C_{2}$ & $C_{1}$ & $C_{2}$ & \\
\hline$A_{1}$ & {$[45,55]$} & {$[45,55]$} & {$[-15,-35]$} & {$[20,35]$} & {$[0.19,0.44]$} & {$[0.25,0.44]$} & {$[0.22,0.44]$} \\
\hline$A_{2}$ & {$[50,65]$} & {$[50,65]$} & {$[-25,-40]$} & {$[15,25]$} & {$[0.31,0.50]$} & {$[0.19,0.31]$} & {$[0.25,0.41]$} \\
\hline$A_{3}$ & {$[25,45]$} & {$[25,45]$} & {$[-5,-15]$} & {$[40,45]$} & {$[0.06,0.19]$} & {$[0.50,0.56]$} & {$[0.28,0.38]$} \\
\hline$A_{4}$ & {$[65,90]$} & {$[65,90]$} & {$[-50,-55]$} & {$[0,0]$} & {$[0.63,0.69]$} & {$[0.00,0.00]$} & {$[0.31,0.34]$} \\
\hline$A_{5}$ & {$[10,40]$} & {$[10,40]$} & {$[0,0]$} & {$[55,50]$} & {$[0.00,0.00]$} & {$[0.69,0.63]$} & {$[0.34,0.31]$} \\
\hline
\end{tabular}

Table 17. The ranking results in the case of grey ideal point

\begin{tabular}{cccccccc}
\hline & & \multicolumn{2}{c}{$\lambda=0$} & \multicolumn{2}{c}{$\lambda=0.5$} & \multicolumn{2}{c}{$\lambda=1$} \\
\hline & $\otimes L_{1, i}$ & $L_{i}$ & Rank & $L_{i}$ & Rank & $L_{i}$ & Rank \\
\hline$A_{1}$ & {$[0.22,0.44]$} & 0.22 & 1 & 0.33 & 1 & 0.44 & 5 \\
\hline$A_{2}$ & {$[0.25,0.41]$} & 0.25 & 2 & 0.33 & 1 & 0.41 & 4 \\
\hline$A_{3}$ & {$[0.28,0.38]$} & 0.28 & 3 & 0.33 & 1 & 0.38 & 3 \\
\hline$A_{4}$ & {$[0.31,0.34]$} & 0.31 & 4 & 0.33 & 1 & 0.34 & 2 \\
\hline$A_{5}$ & {$[0.34,0.31]$} & 0.34 & 5 & 0.33 & 1 & 0.31 & 1 \\
\hline
\end{tabular}

As can be seen from tables 15 and 17, both approaches give the same ranking orders. However, we consider that the use of the grey ideal point is much more logical based.

Dragisa STANUJKIC was born in Serbia in 1964. He received his BSc degree in Mechanical Engineering from the Technical Faculty in Bor in 1988. He received his MSc degree in Information Systems in 1993, and his PhD in 2008, from the University of Belgrade. D. Stanujkic is currently an associate professor in the Department of Information Technology at the Faculty of Management of Megatrend University in Belgrade. His research interests are decision-making theory, expert systems and intelligent decision support systems.

Sanja STOJANOVIC was born in Bor, Serbia, in 1975. She received her BSc degree in Computer and Mathematical Sciences at the Faculty of Natural Sciences in Nis, Serbia, in 1999, as the best student in her generation class. MSc degree received in 2009, in Economics at the Faculty of Management in Zajecar, Megatrend University Belgrade, Serbia. Her current research interests include decision making theory, econometric, business statistics and project management.

Rodoljub JOVANOVIC was born in Zajecar, Serbia, in 1946. He received his BSc degree in Mineral Technologies at the Faculty of Mining and Metallurgy of Bor, Serbia, in 1973, and MSc degree in Economics at Megatrend University in Belgrade, in 2005. He received his $\mathrm{PhD}$ degree also at Megatrend University, in 2007. He is currently working as an associate professor in the Department of Production 
Management at the Faculty of Management in Zajecar, Megatrend University Belgrade, Serbia. His current research interests include production management in complex manufacturing systems, with special interest in production of copper ore concentrate.

Nedeljko MAGDALINOVIC is the Dean of the Faculty of Management Zajecar, Megatrend University in Belgrade, Serbia. He has a PhD in Mineral Technologies, obtained in 1979. He is a regular member of the Balkan Academy of Sciences of Mineral Technologies and a member of the Academy of Engineering Sciences of Serbia. His current research interests include decision-making theory, project management and technological processes of preparing and concentrating mineral raw materials. 